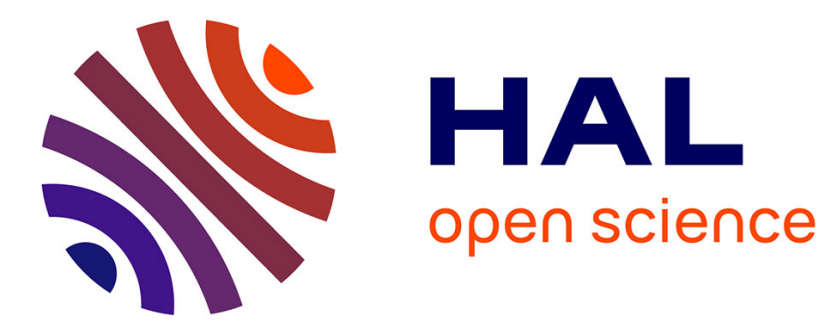

\title{
Diversity hotspots: Coldspots of speciation?
}

Hélène Morlon

\section{To cite this version:}

Hélène Morlon. Diversity hotspots: Coldspots of speciation?. Science, 2020, 370 (6522), pp.1268-1269. 10.1126/science.abf0830 . hal-03089212

\section{HAL Id: hal-03089212 https://hal.science/hal-03089212}

Submitted on 28 Dec 2020

HAL is a multi-disciplinary open access archive for the deposit and dissemination of scientific research documents, whether they are published or not. The documents may come from teaching and research institutions in France or abroad, or from public or private research centers.
L'archive ouverte pluridisciplinaire HAL, est destinée au dépôt et à la diffusion de documents scientifiques de niveau recherche, publiés ou non, émanant des établissements d'enseignement et de recherche français ou étrangers, des laboratoires publics ou privés. 


\section{Diversity hotspots: coldspots of speciation? Phylogeny of suboscine passerine birds finds lower speciation rates in biodiverse regions By Hélène Morlon}

From the tropical Andes to the Mediterranean Basin, some regions of Earth host a remarkable number of species compared to less diverse regions. Robust species-level phylogenies (which map evolutionary relatedness) obtained from genetic sequencing are key for understanding the ecological and evolutionary processes at the origin of such species richness gradients. Yet, they are still incomplete for species-rich groups, even among the most studied organisms such as birds. On page XXX of this issue, Harvey et al. (1) assemble an impressive phylogenomic dataset for the largest Neotropical bird group, the suboscine passerine radiation. Their analysis of these data suggests that species origination is slower, rather than faster, in hotspots of suboscine diversity, and that time, rather than speciation rates, explains suboscine diversity gradients.

Species-level phylogenies have been instrumental in understanding the origin of biodiversity hotspots and richness gradients. Coupled with geographic data and models of speciation and extinction, comprehensive phylogenies provide useful information about the pace of diversification (the balance of speciation and extinction) in space and time (1-7). Yet, large-scale phylogenetic trees are often constructed with few genetic markers, or even by including species without genetic data. Increasing the robustness of these trees is important to obtain robust diversification rate estimates. As Harvey et al. show, their analyses on a less robust suboscine tree (2) would not have detected the negative association between present-day speciation rates and species richness.

The relationship between existing species richness and speciation rates has often been discussed in the context of understanding why biodiversity peaks in the tropics. Different hypotheses for this latitudinal gradient in diversity lead to different predictions regarding diversification rates (8). According to the time hypothesis, the tropics are older and therefore have had more time to accumulate species, even in the absence of any difference between tropical and temperate diversification rates. Whereas the diversification rate hypothesis posits that the

IBENS, CNRS UMR 8197, PSL Research University 46 rue d'Ulm, 75005 Paris, France.

Email: helene.morlon@bio.ens.psl.eu tropics accumulate species faster, either because they are 'a cradle' of biodiversity with high speciation rates, or because they are 'a museum' of biodiversity with low extinction rates. Until recently, phylogenetic and paleontological data generally supported the diversification rate hypothesis, with evidence for higher speciation rates in the tropics where diversity peaks (8).

The negative association between speciation rates and species richness found by Harvey et al. contravenes this evidence, echoing recent studies in birds at different elevations (5) and latitudinal studies in fish (6) and flowering plants (7). Harvey et al. suggest that species-rich areas are coldspots rather than hotspots of speciation, and that the diversity of these areas is explained by their old age and/or low extinction rates. If this interpretation is correct and the results shared with other species groups, focus may need to change from understanding why speciation rates are higher in biodiverse regions such as the tropics to understanding why they are lower. But, should conclusions be drawn so hastily?

Recent studies have focused on speciation rates 'at the tips' of phylogenies, i.e. present-day speciation rates (9). Earlier studies based on sister species comparisons and therefore also focused on the recent past had also found lower speciation rates where biodiversity peaks (10). By contrast, studies integrating information from the distant past have often found higher speciation rates in diversity hotspots $(3,4,8)$. Therefore, one explanation for the apparent paradigm shift is that current hotspots of biodiversity were once hotspots of speciation, but speciation rates decreased drastically in these areas to reach present-day levels below those of species-poor areas. Such a decline in speciation rate is expected if species richness has an upper limit set by environmental conditions such as resource availability (11). Under this 'ecological limits' hypothesis, regions that accumulated species rapidly in the past are closer to their biodiversity capacity than species-poor regions, and are therefore less prone to present-day speciation.

Harvey et al. found mixed support for this hypothesis. The best model to fit their phylogenetic tree is one that contains a causal link between climatic variables and species richness, and an inverse correlation between species richness and speciation rates. This suggests that the number of species in a given region modulates speciation rates. Conversely, Harvey et al. did not find evidence for the speciation slowdown expected under the ecological limits hypothesis. Given that the existence of ecological limits is highly debated (12), additional evidence is needed, or other plausible explanations should be investigated.

The analysis by Harvey et al. of recent speciation rates, along with that of others (57), forces reconsideration of traditional evolutionary hypotheses for explaining richness gradients. However, recent speciation rates are only one piece of the puzzle. A thorough understanding of species richness gradients requires mapping speciation and extinction rates to geography not only in the present, but also in the past, while allowing these rates to vary through time. This is a challenging task, but not one that cannot be tackled. For example, geographically-dependent diversification models have allowed estimation of temporal variations in tropical and temperate speciation rates (3). An alternative approach for mapping past rates to geography is to couple recent approaches that allow estimation of lineage-specific diversification rates (13) to ancestral biogeographic reconstructions. Given that speciation rates estimated from only extant data have diminished reliability for historical rates, and that extinction rates, which may play an important role in modulating richness gradients, are notoriously difficult to estimate from reconstructed phylogenies (14), further efforts to incorporate direct information from the past (i.e. fossils) will be particularly useful (15).

The assembly and analysis of comprehensive phylogenomic data for the largest tropical bird radiation by Harvey et al. contributes to mounting evidence that new species may not always be generated in biodiversity hotspots. These findings suggest a new burning question: Have diversity hotspots always been coldspots of speciation, or did they turn from hotspots to coldspots of speciation as diversity accumulated?

REFERENCES AND NOTES 


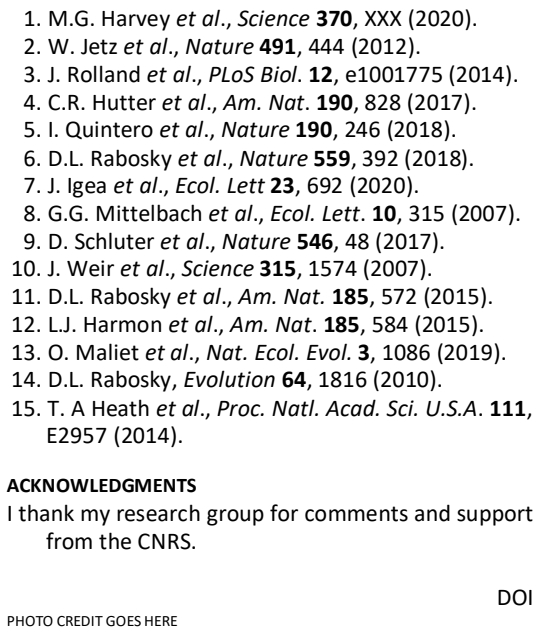

